\title{
The impact of turnover rate for the decision of job-training investment
}

\author{
Shaozeng Dong, Xiaoling Wang
}

Harbin University of Science and Technology, Weihai, Shandong

\begin{abstract}
Job training is an important way to increase the high-skilled human capital stock, so it's becoming a hot topic in business management. Because the departure of some trained staff, many companies do not know whether it should do job training. This paper trough analyzes the relationship between the turnover rate of trained staff turnover rate and the investment decision of job training, and provides some decision support for enterprise's manager.
\end{abstract}

Keywords: Job-training; Human Capital Investment; Turnover Rate.

\section{Introduction}

With Becker's human capital theory put forward, especially in the current era of information technology, due to accelerate technical information update rate, the growing demand for the professional skills, job training as a flexible form of investment in human capital, more and more attention to corporate organization. Enterprise-job training as an important form of human capital investment is an important way for enterprises to obtain highly skilled personnel. Studies have shown that $90 \%$ of job skills is through "re-education" or "reproduction of human capital" approach to achieve. Companies can improve employee skills through in-service training to improve labor productivity, improve the core competitiveness of enterprises, at the same time, in favor of scientific and technological achievements, but at the same time corporate job training also faces enormous risks. Job training as a form of human capital investment, compared with physical capital investment, which is a more complex and more uncertain investment behavior, greater investment risk ${ }^{[1]}$. This is where the trained employee turnover dedication, the biggest impact on business. Trained especially after training to enhance the skills of staff turnover, not only loss the business-service training costs, but also may lead to enterprise core technology and the loss of a large number of customers, it caused irreparable damage to the organization. Therefore, companies have chosen the-job training to improve staff skills in the process, we will consider staff turnover rate. Research on the influence of turnover to Job Training Decision, we can provide more decision support for enterprises.

Enterprises in their development process, need to constantly get highly skilled human capital to improve their market competitiveness, and directly through the external hiring ways and can not meet the business demand for high-skilled human capital, which makes the way enterprises are turning to in-service training. Education and training are two basic ways of human capital investment, compared with the education, training closer to the labor market, the accumulation of knowledge through training and skills are more easily converted into real productivity ${ }^{[2]}$. But also through in-service training for employees, can increase their stock of human capital; improve labor productivity of employees, thereby forming elements of increasing returns ${ }^{[3]}$. Enterprise-job training is not expenditure but an investment. The-job training in the organization of enterprises, you first need to define training needs and organizational needs of employees, only when both the needs of fit, we can carry out job training, and to evaluate job training program ${ }^{[4]}$. Meanwhile, in order to enhance job training effect, we can adopt a flexible training wage, can effectively improve the quality of in-service training, improve labor productivity, improve employee loyalty, and improve relations employees and enterprises ${ }^{[5]}$.

The-job training as an important form of human capital investment is gaining access to high-skilled human capital, improve organization of human capital, an important way to enhance labor productivity. The-job training is not only reflected in the development of basic vocational skills, while enterprises are also enterprises to create intellectual capital, increase enterprise "think tank," the basic approach, meanwhile through job training, allowing trained staff to better integrate into the organizational culture and improve employee loyalty, improve the competitiveness of enterprises. 


\section{2. employee turnover intention}

Human capital investment as an aspect of corporate capital investment, but also faces many risks. The-job training as an effective means to enhance the comprehensive competitiveness of enterprises is an important form of human capital investment. However, the final result of the training, if trained staff especially skills upgrading employee turnover and other phenomena exist, will result in a wide range of business losses, it has also become a problem that plagues many companies - job training investment decisions ${ }^{[6]}$.

Employees participating in job training enterprises, will face the risk of future job uncertainty, however, the possibility of such future changes also affected the position of their own employees to participate in enterprise-job training initiative, when the job training enterprise investment decisions will consider the possibility of leaving employees, companies do not want to leave the organization or the upcoming post-job training employees ${ }^{[7]}$.

So-called departure intend for prediction of enterprise employee turnover rate is an important antecedent ${ }^{[8]}$, refers to a psychological tendency of employees to leave the current job performance ${ }^{\text {[9] }}$. Investment decision of job training and trained staff turnover intention there is a close link. On the one hand, after employees participate in job training organization, to learn more about business and better integrate into the corporate culture and improve employee loyalty to the organization, reducing its turnover intention; on the other hand, after the staff training, due to the growth of their own skills and abilities, especially the growth of highly skilled knowledge workers, the willingness to change the status quo will be more intense. If a period of time after the training, their condition is not improved; the staff will produce greater willingness. Research shows that highly skilled knowledge workers will pay as a measure of a reflection of their own values ${ }^{[10]}$, so, after-the-job training, business organizations need to rebuild human capital compensation system to enhance the organization trained staff loyalty, reduce employee turnover intention.

\section{Job training investment options}

Enterprise on-the-job training as an important form of the enterprise human capital investment, while brings to the enterprise human capital growth, will face some risks. Enterprises in job training investment decisions depend primarily on three aspects ${ }^{[11]}$ : (1) the possibility of employee turnover that is the a priori probability of employee turnover. Trained staff's departures will strongly, the turnover will be after the training, after training its turnover will be greater, enterprise-job less likely to invest in training; (2) Staff skill promoting effects on the labor productivity. On-the-job training of enterprise investment decision, the purpose is to improve the skill levels of employees, improve labor productivity, increase profits. Therefore, the degree of skill training employees also is one of the main factors - job training investment decisions when considering; (3) the successful conversion of inservice training. Due to differences in trained staff own quality, employees receiving job training, can not get the degree of skill level, therefore, the successful conversion of the-job training has a direct impact on corporate job training investment decisions. Companies through job training way to get enterprise human capital stock growth, the job training costs must be less than through external hiring of access to equal human capital investment. Therefore, necessary condition for gaining access to $\mathrm{m}$ highly skilled human capital through job training is:

$$
\mathrm{f}(\mathrm{m})=\mathrm{mg}-\mathrm{mc} \geq 0
$$

Wherein, $\mathrm{f}(\mathrm{m})$ represents obtain $\mathrm{m}$ high-skilled human capital investment in the difference between the stock of human capital through job training and external hiring two ways; g represents obtain a high-skilled human capital investment through external hiring approach; c represents obtain a high-skilled human capital training investment by way of job training.

Combining Fan Xiu meteor on-the-job training offered by the investment decision-making based on three aspects, our trained staff turnover rate increase p, and trained staff from low to high skill level skill level of success the conversion of two variables $r$, reconsider the necessary conditions for enterprises to obtain m highly skilled human capital through job training approach: 


$$
\mathrm{f}(\mathrm{m})=\mathrm{mg}-\frac{\mathrm{mc}}{(1-\mathrm{p}) \mathrm{r}} \geq 0
$$

From the perspective of human capital investment, only under the premisef $(m) \geq 0$, companies will get job training needed by highly skilled human capital stock, and the greater $f(m)$, the strong willingness of enterprises investment decision-job training; conversely, iff $(\mathrm{m}) \leq 0$, the company will give job training investment favor to get enterprise highly skilled human capital stock by way of external hiring.

Under certain conditions, companies hire highly skilled human capital stock to obtain the per capita investment in g and obtaining high-skilled human capital stock per capita investment in job training by an external c is stable, successful transformation rate shows that the higher the job training corporate investment decisions willingness job training more intense, fewer trained staff turnover rate p, investment decision-making enterprise-job training is also more intense.

Therefore, when companies - job training investment decisions, but also through the organization to guide and organize incentives, etc., to improve employee job training initiative, to enhance employee loyalty, thereby reducing staff turnover rate, ensure the effectiveness of job training. 4 Investment benefit analysis of job training

Enterprises to obtain high-skilled human capital stock through job training approach, its fundamental purpose are to improve labor productivity, enhance competitiveness and increase corporate earnings. Therefore, the efficiency of enterprises job training investment must be positive, only positive investment returns, enterprises can carry out the wishes of job training investment.

Assuming that enterprise human capital amount of size $n$, the enterprise business performance ${ }^{\pi} 0$ in front of the on-the-job training can be expressed in the type:

$$
\pi_{0}=\mathrm{nD}_{0}-\mathrm{nW}_{0}
$$

Where D0, is pre-training low-skilled human capital per capita output; W0, is the per capita cost of production before training low-skilled human capital.

So, through job training investment, the company's human capital skills are improved to some extent, and grow into A highly skilled human capital, after the training of expected output per capita is $D_{1}>D_{0}$; meanwhile, Due to the highly skilled manpower capital still attaches great importance to the compensation, So highly skilled human capital cost of production per capita $\mathrm{W}_{1}>\mathrm{W}_{0}$, and $\mathrm{D}_{1}-\mathrm{D}_{0}>\mathrm{W}_{1}-\mathrm{W}_{0}$, namely marginal job training in human capital output ratio $\phi=\frac{\mathrm{D}_{1}-\mathrm{D}_{0}}{\mathrm{~W}_{1}-\mathrm{W}_{0}}>0$. Then job training investment enterprise after enterprise efficiency can be expressed as:

$$
\pi_{1}=\mathrm{nr}(1-\mathrm{p})\left(\mathrm{D}_{1}-\mathrm{W}_{1}\right)+\mathrm{n}(1-\mathrm{r})\left(\mathrm{D}_{0}-\mathrm{W}_{0}\right)-\mathrm{nc}
$$

Enterprises to make investment decisions on-the-job training must meet:

$$
\pi_{1}-\pi_{0} \geq 0
$$

Solving drawn: $\quad \mathrm{p} \leq 1-\frac{\mathrm{D}_{0}-\mathrm{W}_{0}}{\mathrm{D}_{1}-\mathrm{W}_{1}}+\frac{\mathrm{c}}{\mathrm{r}\left(\mathrm{D}_{1}-\mathrm{W}_{1}\right)}$

If the output growth of human capital $f=\frac{D_{1}-W_{1}}{D_{0}-W_{0}}$, human capital training ROI is $\mu=\frac{\left(D_{1}-W_{1}\right)}{c}$, then

$$
\mathrm{p} \leq 1-\frac{1}{\mathrm{f}}+\frac{1}{\mathrm{r} \mu}
$$

Business investment decisions during job training, its human capital output growth $f$ and human Capital Training ROI ${ }^{\mu}$ will have a base value prediction, therefore, turnover rate $\mathbf{p}$ and successful conversion of on-the-job training $\mathbf{r}$ is inversely, namely, the higher the success rate of on-the-job training, the lower the staff turnover rate. Studies have shown that job Training high success rate 
conversion, can enhance employee confidence in the organization, and improve organizational employee loyalty, and reduce employee turnover.

\section{Conclusions}

Enterprises in job training investment decisions, commitment to employees is a long-term growth opportunities, is a desirable opportunity. Enterprises in job training investment decisions, to consider not only job training program itself, but also by other supporting incentives to enhance the active participation of employees, increase the success rate of the conversion job training, thereby reducing training staff turnover rate, increase business highly skilled human capital stock, to achieve enterprise efficiency purposes.

\section{Reference}

[1] Wei Ren. Risks and countermeasures of enterprise job training investment [J]. Journal of China finance and economics politics and law university graduate students, 2006, (3): 93-97.

[2] Xiangping Li. Affect in-service training for employees' income growth [J]. Chinese Vocational and Technical Education, 2007 (8): 5-8.

[3] Fang-wei Zhu, Chun-you Wu. Based on the employee loyalty of on-job training investment decision-making research [J]. Journal of dalian university of technology (social science edition), 2003, (1): 38-41.

[4] KS Subramanian, Vinita Sinha ,Priya D Gupta. A Study on Return on Investment of Training Programme in a Government Enterprise in India[J]. The Journal for Decision Makers, 2012,(31):31-48.

[5] Anne C. Gielen. Profit Sharing for Increased Training Investments[J]. British Journal of Industrial Relations, 2011(12):643-665.

[6] Qian Yang, Hong Gu. Trained staff training investment decisions under the influence of the loss risk [J]. Journal of xi 'an university of technology, 2014, (3): 228-231.

[7] Loewenstein, M. and Spletzer, J. Delayed formal on-the-job training[J]. Industrial and Labor Relations Review, 51 (1): 82-99.

[8] Shore L M, Martin H J. Job satisfaction and organizational commitment in relation to work performanceand turnover intentions[J]. Human Relations, 1989,42(7):625-638.

[9] Mobley WH, Horner SO, Hollingworth AT. An evaluation of precursors of hospital employee turnover[J].Journal of Applied Psychology, 1978,63(4):408-414.

[10] Qinghong Yuan, Gang Ding, Hui Li. Knowledge workers career growth and turnover intention - organizational identity and professional identity of regulation [J]. Science of Science and Management, 2014, (1): 155-164.

[11] Xiu- liao Fan, Qiang Li. The influence of enterprise on-the-job training for the workers wages [J]. Journal of south China normal university (social science edition), 2012, (5): 108-112. 